\title{
(DES) CONTRUÇÃO DO MITO DA “VERDADE REAL" E O PAPEL DO MAGISTRADO NO PROCESSO PENAL ENQUANTO INSTRUMENTO CONSTITUCIONAL
}

\author{
Leonardo Biagioni de Lima \\ leonardobiagioni@hotmail.com
}

\section{RESUMO}

Tem-se procurado utilizar o processo penal como meio de se perseguir e constituir uma verdade real acerca dos fatos pretéritos que estão sendo investigados, desvirtuando funções dos agentes judiciários e transpassando as garantias do acusado. Destarte, verificar-se-á, através de um prisma filosófico-jurídico, a ideia de verdade, sua convalescência no processo penal, o papel do magistrado na sua incursão, bem como a constitucionalidade desse princípio, preocupando-se em desconstruir esse mito que parece, para muitos juristas, já consagrado no processo penal.

Palavras-chave: processo penal; modelo garantista; teoria do conhecimento; verdade real.

\begin{abstract}
It's been sought to use the criminal procedure as a means of pursuing and constituting a real truth about past events that are being investigated, perverting the functions of the judicial agents and transpassing the defendant's guarantees. Thus, the idea of truth, its convalescence in the criminal procedure, the judge's role and the constitutionality of this principle will be verified through a philosophical-legal prism, focusing on deconstituting this myth which seems, to many jurists, to be already established in the criminal procedure.
\end{abstract}

Keywords: criminal procedure, garantistic model; knowledge theory; real truth.

\section{Modelo Substancialista e Modelo Formalista (Instrumentalidade Constitucional)}

O Processo Penal, em pleno início do século XXI, parece, ainda, carregar algumas marcas de um período totalitário e, por assim dizer, absolutista, que por muito tempo vigorou e assombrou o Homem.

Nossa legislação, apesar de muitas reformas, se mantém arraigada a um modelo processual penal em que se busca dirimir um fato, condicionalmente delituoso, passando por cima de tudo e de todos, não respeitando sequer a Lei Maior.

A despeito de possuirmos uma Constituição garantidora de um devido processo legal, suportado por uma visão acusatória, observamos um Código de Processo Penal com remanescentes normas inquisitivas, verificando um sistema antigarantista, 
carregado de aspectos subjetivos, desaguando num direito penal (material e formal) que se aproxima de um modelo substancialista ${ }^{1}$.

O conjunto desses aspectos substancialistas acaba influenciando no propósito epistemológico do processo, qual seja assimilar os acontecimentos passados e procurar evidenciá-los a fim de se estabelecer se tal fato corresponde a um desvio punível, penalmente tutelado.

Deste modo, a "verdade jurídica" perseguida por esse modelo é feita sem observação de regras e garantias, através de um cognitivismo ético, por demasiado arbitrário. Busca-se, assim, uma utópica verdade a todo custo.

Por outro lado, com base em um sistema acusatório-garantista de instrumentalidade processual, existe o modelo formalista ${ }^{2}$, possuindo como objetivo o respeito às regras e aos direitos individuais do acusado. É, destarte, adstrito tão somente a circunstâncias definidas como penalmente relevantes, sem almejar "descobrir" a verdade dos fatos. Possuindo um anseio constitucional ao processo.

Esses dois modelos se contrapõem e dividem juristas quanto ao dever de aplicar um ou outro sistema em nosso direito criminal.

Um paradoxo, a partir daí, pode ser notado entre a verdade formal e a verdade substancial: Desprezar as regras constitucionais do jogo e se chegar à verdade ou agir conforme as garantias penais e processuais e posicionar-se no que concerne aos elementos circundantes ao fato (à verdade)?

Eis que, na procura de se solver tal contradição, surgem algumas considerações: a) realmente há como saber toda a verdade dos fatos? b) Há como reconstruir de modo equânime os acontecimentos passados? c) A verificação real deve ser almejada pelo magistrado?

\section{Uma Visão Acerca da Verdade}

Quando tratamos de constatações pretéritas, estamos falando de atos já realizados no tempo, encontrando-se, assim, acabados, construídos. Consoante toda

\footnotetext{
${ }^{1}$ FERRAJOLI, Luigi. Direito e Razão: teoria do garantismo penal. 3.ed. rev. São Paulo: Revista dos Tribunais, 2010. p. 44-45, define o modelo substancialista como um cognitivismo ético. Atrelado à moral, acaba transpassando a legalidade, que em se tratando de ciência penal deveria ser estrita (estrita legalidade). Desse modo, desemboca numa figura antigarantista, produzindo um modelo processual penal inquisitivo.

${ }^{2}$ Contrapondo-se ao substancialismo, FERRAJOLI conceitua o formalismo como um modelo ideal de se fazer valer a garantias do indivíduo frente ao processo, através do qual os princípios penais e processuais penais são observados a fim de se fazer valer o devido processo legal. Ob. Cit. p. 48.
} 
teoria científica restada concluída, não mais há de se observar diretamente a maneira que se desenvolveram seus elementos como, de outra forma, poder-se-ía se tratasse de proposições empíricas de observação.

Pode-se, do mesmo modo, dizer das verificações processuais, que não subsistem ao enredo que fora fechado pelo tempo, sobrando tão somente a ser apreciado um conjunto metodológico de presunções (induções e deduções), pois os fatos não estão mais disponíveis para experimentação.

Quaisquer procedimentos quando findos não parecem mais poder ser reproduzidos conforme o foram, pois uma vez que a cena não mais pode ser vivenciada, há que se analisar as questões que a circundam. Destarte, o que se pode obter são indícios, presunções através de pessoas e objetos e, assim, são constituídas as provas.

Assim, a relação da verdade fática junto à verdade jurídica é consubstanciada em uma inferência indutiva referente ao que se constatou das verificações probatórias e o fato que cabe ser analisado ligando-se à norma, ou seja, o que se está preceituado no ordenamento como desvio punível.

O magistrado, agente final nesse iter processual, ignora os fatos históricos, assim, necessita de alguém (ou algo) que o elucide, o que será feito através de um exercício recognitivo, - contrapondo-se ao cognitivismo que seria um "conhecer experimental", onde é um exercício de análise do presente - contudo, nada ou ninguém será capaz de trazer a totalidade dos fatos e é ainda mais ousado dizer que a partir do mínimo trazido se reconstituirá o "real" fato ${ }^{3}$.

A reconstrução de qualquer fato se perde no tempo, é imperfeita, mínima e modificada, fica, desse modo, presa à memória do narrador. Dialogando com a Literatura, percebemos o papel de Machado de Assis, em Dom Casmurro, no qual, como sabe-se, leva a crer que Capitu traíra Bentinho, mas esse é o ponto de vista de Bentinho, que é o autor da narração. Se o prisma ótico fosse feito através de Capitu seria narrado do mesmo modo? Os fatos seriam descritos da mesma maneira? A verdade muitas vezes é impossível de ser reconstruída, o que realmente parece restar são as observações através de resultados.

\footnotetext{
3 No estabelecer da verdade mediante a correspondência da enunciação com seu objeto, HEIDDEGER afirma que a essência da verdade (ontológica) está acima do ser humano. Não sendo possível ser conhecida pelo Homem, que é instável, ao passo que é tida pela metafísica como eterna e imperecível. Do mesmo modo CHIMENTI, Francesco. O processo penal e a verdade material. Teoria da prova. Rio de Janeiro: Forense, 1995. p. 49, para quem a verdade suprema, transcendental está fora do alcance humano.
} 


\section{A Verdade Processual}

Como analisado, a verdade em si parece ser um caminho impossível de se chegar, não há que se ter a ambição de reconstituir o passado tal qual o foi. O que se deve deslumbrar são constatações acerca dos acontecimentos, aquilo que foi trazido ao processo como prova.

Nenhuma verdade encontra-se construída sobre o cimento. A verdade é constituída em certo lapso temporal e ali é soberana, no entanto possui prazo de validade, ainda que, na oportunidade, parecia ser incontestável.

Tais constatações levam a crer que o processo não deve almejar construir uma verdade notória, digna de aplausos, que se oponha às garantias individuais, afim de decifrar os acontecimentos passados, uma vez que essa "verdade real" não existe, é irreal e quanto mais a busca, mais longe da realidade parece estar. Basta lembrar o período inquisitivo, no qual eram permitidas as torturas, para que se buscasse a confissão do acusado. Inúmeros inocentes foram considerados culpados, tudo por causa de um método terrorista e antigarantista de se perseguir uma utópica realidade.

O processo deve servir como instrumento para que se chegue, respeitando os limites constitucionais, às presunções deixadas pelo resultado do fato que está sendo conhecido através da tutela jurisdicional. As provas, portanto, são uma representação dos acontecimentos e não uma metalinguagem em que reproduzir-se-á os fatos em si mesma. Assim, não são um meio para determinar a verdade, e sim indicar.

Desse modo, a verdade processual não é uma "verdade" propriamente dita, mas o conjunto das especulações trazidas pelas partes e apreciadas pelo juiz ao longo do processo, consubstanciando-se em uma verdade formal, condicionada pelo respeito ao procedimento e às garantias. Não formará, portanto, um juízo de certeza, mas sim de probabilidade.

\section{Os Princípios Constitucionais e sua (não) Relação com a Verdade Processual}

\subsection{Princípio da Imparcialidade do Juiz}

Durante todo o processo, o magistrado deve-se manter equidistante das partes, não podendo favorecer qualquer uma delas, seja autor ou réu. Essa neutralidade faz-se 
necessária para que o juiz atenha-se tão somente aos aspectos objetivos da causa, não se deixando levar por aspectos pessoais.

Para que, efetivamente, não haja tais imparcialidades, causando irregularidade ao processo, o Código disponibiliza meios para se combater essa postura tendenciosa do juiz, preceituando os casos em que o juiz deve-se considerar suspeito ou impedido (artigos 252 a 256, do Código de Processo Penal) e a forma de se alegar tal exceção (artigo 95 e seguintes, do referido diploma).

Portanto, nota-se que o juiz deve manter uma relação equilibrada com as partes, deixando-as cumprir suas funções, sem intervir (seja favorecendo ou atrapalhando). Porém, no próprio Código de Processo Penal verificam-se contradições, pois a despeito de constar tais exceções para proteger o processo de juízes imparciais, encontram-se normas que dão poderes investigativos ao juiz, fazendo com que este funcione como parte no processo, voltando-se a agir conforme outrora, numa época inquisitiva, na qual o magistrado acumulava as funções de julgar, acusar e defender.

Exemplificando, o artigo 209, caput, CPP, preconiza que "o juiz, quando julgar necessário, poderá ouvir outras testemunhas, além das indicadas pelas partes" "4. Destarte, vê-se que o juiz tem o poder de arrolar testemunhas, funcionando como parte no processo. Assim, caso as testemunhas de acusação não tenham atendido o animus puniendi, possibilitaria ao magistrado arrolar testemunhas para que possa ver condenado o atual acusado.

Está-se, desse modo, diante de um processo inquisitivo, no qual o juiz conjuga as três funções dentro do processo, - acusar, defender e julgar - buscando dirimir os fatos, extrapolando suas funções judicantes e participando de atos postulatórios que deveriam ater-se apenas a autores e réus. Realiza, imaturamente, tais funções, em busca de uma verdade que não existe (como verificou-se), além de que essa prerrogativa dada ao juiz o torna tendencioso. Assim o procedimento correto seria de impedi-lo de continuar perante a causa. Embora, como se sabe, não seja isso que ocorra em nosso sistema processual penal.

\footnotetext{
${ }^{4}$ No julgamento (Apelação Crime No 70017773078, Oitava Câmara Criminal, Tribunal de Justiça do RS, Relator: Roque Miguel Fank, Julgado em 13/06/2007), observou-se a seguinte fundamentação para que fosse concedido ao juiz ouvir mais testemunhas que as possibilitadas para as partes: "Ao julgador é facultada a ouvida de outras testemunhas, além das indicadas pelas partes, quando for conveniente à instrução penal, na busca a verdade real". Prevalecendo-se, assim, o princípio da "verdade real" frente o

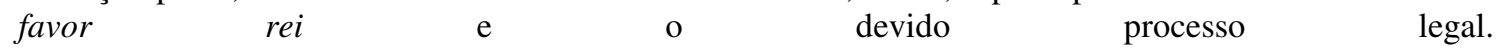


4.2. Princípio da Presunção da Inocência, do Favor Réu (favor rei) e da Igualdade Processual

Conjuntamente ao princípio da imparcialidade do magistrado, deve posicionar os princípios da presunção da inocência, da igualdade processual e sua consequência, o favor rei, elucidados pelo artigo $5^{\circ}$, caput e inciso LVII, da Constituição Federal.

Esses princípios reunidos têm por objetivo fazer valer a igualdade das partes no processo, de modo que o réu, parte mais frágil dentro da relação processual, não seja visto como um objeto, mas sim um sujeito de direitos. Só assim haverá uma efetiva isonomia processual (isonomia material).

A partir disto, observa-se que o acusado possui um amplo espectro de garantias constitucionais que o beneficiam durante as investigações e a tramitação da ação penal ${ }^{5}$, o que nos remete a um sistema garantista, pelo qual o indivíduo, que suporta contra si uma acusação, tem direitos e garantias individuais em sua imagem e moral. Portanto, o que deseja nossa Lei Maior não são essas atrocidades que se verificam muitos vezes na lei infraconstitucional, insegura e antigarantista, mas sim um modelo formalista de se ver e construir o processo, usando-o como instrumento constitucional, como forma de, então, se fazer justiça. Justiça essa segura, consciente e racional.

Nenhum acusado deve ser punido sem que subsistam fundadas acusações contra si e que estas sejam comprovadas ao longo da persecução penal. Isso decorre de que nulla poena sine culpa e nulla accusatio sine probatione. Portanto, é papel do Acusador (Ministério Público ou ofendido) evidenciar as acusações feitas através de provas, afim de que essas sejam verificadas pelo órgão julgador. Assim como é dever do Defensor, apenas trazer à relação processual as causas de exclusão da culpa, contestando as alegações feitas pela outra parte, pois o imputado é presumidamente inocente, não lhe incumbindo provar nada, uma vez que nada restando comprovado será este inocentado. Apesar de, infelizmente, não ser o que se observa muitas vezes nas decisões judiciais ${ }^{6}$.

\footnotetext{
5 SARMENTO, George. A presunção da inocência no sistema constitucional brasileiro. In: Direitos fundamentais na Constituição de 1988: estudos comemorativos aos seus vinte anos. Rosmar Antonni Rodrigues Cavalcanti de Alencar (org.). Porto Alegre: Núria Fabris, 2008. p. 242-243.

${ }^{6}$ A respeito do tema, acórdão do Superior Tribunal de Justiça: PENAL E PROCESSUAL. HOMICÍDIO CULPOSO EM CONCURSO FORMAL. CONDENAÇÃO. TRÂNSITO EM JULGADO. ALEGAÇÃO DE INOCÊNCIA. PRINCÍPIO DA BUSCA DA VERDADE REAL. MATÉRIA PROBATÓRIA. PRESCRIÇÃO DA PRETENSÃO PUNITIVA DO ESTADO. "SURSIS" PROCESSUAL. AUSÊNCIA DE ELEMENTOS PARA ANÁLISE DOS PEDIDOS. NÃO CONHECIMENTO.
} 
Deste modo, infere-se que a carga probatória fica por conta do órgão de acusação, o qual deve levar ao magistrado suas teses com o fulcro de restarem verificadas e somente assim o serão se, efetivamente, comprovadas. Assim se estabelece a relação jurídica: a uma parte cabe a alegação, à outra os fatos excludentes de tais alegações (se os houver) e ao juiz a análise de todas as hipóteses, "aceitando a acusatória somente se estiver provada e, não a aceitando, se desmentida ou, ainda que não desmentida, não restar suficientemente provada" ${ }^{\text {. }}$.

Seria, portanto inconstitucional o artigo 156 , inciso II, do $\mathrm{CPP}^{8}$, suporte dos doutrinadores que vêem a busca pela verdade real como o ápice da justiça processual, diante da manifesta contradição com o in dúbio pro reo. Ao final do percurso, apresentadas as alegações, mostradas as defesas, cabe ao magistrado julgar os fatos e hipóteses a ele apresentados. Comprovada a alegação, verificar-se-á a acusação e será o réu, só agora, considerado culpado e possuirá contra si uma sentença condenatória transitada em julgado. Se não verificadas as alegações trazidas pela acusação ou refutadas pelas teses defensivas, o acusado será considerado inocente. Por último, subsistindo dúvida aplicar-se-á o imperativo de se favorecer o réu, afim de que nenhum inocente seja vítima quando da decisão processual.

Apesar disso, doutrinadores ainda consideram fundamental a busca pela verdade real para que se estabeleça o jus puniendi, devendo o juiz "dar seguimento à relação processual quando da inércia da parte e determinar, ex officio, provas necessárias à instrução do processo, afim de que se possa, tanto quanto possível, descobrir a verdade dos fatos objeto da ação penal" 9 .

Deixar de aplicar o imperativo princípio do in dubio pro reo afim de se obter maiores informações é uma afronta grotesca às garantias processuais e à segurança jurídica. $\mathrm{O}$ acusado tem o direito de ver-se inocente em caso de dúvida. Não pode

(HC 27062 / SC - Processo 2003/0023711-8 - Min. Relator: PAULO MEDINA - Órgão Julgador: $6^{\mathrm{a}}$ Turma - Data do Julgamento: 23/11/2004 - Data da publicação/ Fonte: 07/03/2005 DJ p. 348.

“Alegações tendentes a refutar a autoria delitiva, com vistas à declaração de inocência, desbordam da via eleita, porque exigem aprofundado exame de fatos e provas. O habeas corpus é ação de rito sumário, que demanda prova pré-constituída e não comporta dilação probatória, exigindo-se para o seu conhecimento a presença de elementos que possibilitem o exame das questões nele suscitadas".

${ }^{7}$ LOPES JÚNIOR, Aury. Introdução crítica ao Processo Penal (Fundamentos da instrumentalidade constitucional). 4.ed. Rio de Janeiro: Lúmen Juris, 2006. p. 189.

${ }^{8}$ O mencionado artigo traz a seguinte redação: "Art.156. A prova da alegação incumbirá a quem a fizer, sendo, porém, facultado ao juiz de ofício: II- determinar, no curso da instrução, ou antes de proferir sentença, a realização de diligências para dirimir dúvida sobre ponto relevante".

${ }^{9}$ MIRABETE, Julio Fabbrini. Processo penal. 18. ed. São Paulo: Atlas, 2006. p. 25. 
subsistir em um Estado Democrático um juiz perseguidor, fazendo as vezes da $\operatorname{acusação~}^{10}$.

Logo, é mais que tempo de se fazer valer tais princípios constitucionais frente a leis antigarantistas, colaboradoras de um modelo substancialista, pelo qual pensa-se estar fazendo justiça social, quando, no entanto (e muito pelo contrário), acaba trazendo excessos e abusos, e, então sim, (grave) insegurança jurídica.

\section{Considerações Finais (afim de se estabelecer um modelo processual garantista)}

É certo que o processo penal existe enquanto instrumento de aplicação da lei material, mas também é certo que deve existir hierarquia no ordenamento jurídico, através da qual as leis infraconstitucionais obedeçam o disposto na Constituição Federal. Chega-se, então, a conclusão que o processo deve possuir uma instrumentalidade constitucional, fazer valer as normas constitucionais nas ações penais.

Quando se faz essa aplicação tem-se um processo à luz da Constituição, ou seja, respeitando garantias, estabelecendo limites e contendo atrocidades, por menores que possam, à primeira vista, parecer.

Através desse processo garantista, facilmente se verifica a falibilidade de uma incursão através da utópica verdade "real", com o pretexto de se trazer segurança ao processo, que conforme exposto é ilusória, não subsiste no tempo e, assim, não será encontrada. Forçar isso é, ao contrário do pretendido, formar um Estado do medo, no qual não subsistiriam direitos, formar-se-ia (como em muitos casos vêm sendo observado) um período do caos, voltando-se a um sistema inquisitivo, de insegurança jurídica.

Deve-se deixar de lado aquele utilitarismo processual que por tanto tempo perdurou e por tanto tempo fez vítimas, não respeitando sequer o Homem, ser criador do Estado e objeto de suas Leis. Até que ponto os fins justificariam os meios? Estaríamos novamente diante de uma teoria das janelas quebradas ${ }^{11}$, suportando esses abusos e falta de limites, em favor de um Estado opressor?

\footnotetext{
${ }^{10}$ Sobre o tema, MONTESQUIEU. Do Espírito das Leis, São Paulo: Abril Cultural, 1979. p. 431. Reflete que "a liberdade política consiste na segurança, ou ao menos na convicção que se tem da própria segurança (...) e se a inocência dos cidadãos não é garantida, tampouco o é a liberdade". Disso decorre que é preferível ser todos os inocentes protegidos, ainda que haja impunidade a algum culpado, a ver a punição de todos os culpados juntamente com inocentes.

${ }^{11}$ Referência à COUTINHO, Jacinto Nelson de Miranda; CARVALHO, Edward Rocha de. Teoria das janelas quebradas: e se a pedra vem de dentro? Disponível em: http://www.parana-
} 
O caminho correto a se dirigir não parece ser esse. Para que haja confiança no poder político, o mínimo que o indivíduo quer e necessita é que sua liberdade e segurança não sejam violadas. O temor dos homens, pactuantes do Contrato Social, deve restar somente às leis. O medo das leis é salutar, no entanto o temor do homem ao próprio homem é fatal e criador dos delitos. "Os homens escravos são mais voluptuosos, mais libertinos que os homens livres" ${ }^{\prime 2}$.

Resta, portanto, que cada agente processual, mantenha seu papel, agindo tão somente dentro de suas funções, principalmente o magistrado, agente que deve ater-se imparcial e equidistante das partes, não substituindo-as em acusações ou defesas, no máximo deve equilibrar a relação processual, colocando o acusado (parte frágil) em pé de igualdade com a parte que o acusa.

Apenas assim verificar-se-á um Estado respeitador da Constituição Federal, resguardando os direitos e garantias fundamentais inerentes ao Homem afim de constituir um "real processo penal".

\section{REFERÊNCIAS BIBLIOGRÁFICAS}

BARROS, Marco Antonio de. A busca da verdade no processo penal. São Paulo: Revista dos Tribunais, 2002.

BECCARIA, Cesare. Dos delitos e das penas. São Paulo: Martin Claret, 2002.

BITTAR, Eduardo Carlos Bianca. Metodologia da pesquisa jurídica. São Paulo: Saraiva, 2001.

CHIMENTI, Francesco. O processo penal e a verdade material. Teoria da prova. Rio de Janeiro: Forense, 1995.

COUTINHO, Jacinto Nelson de Miranda; CARVALHO Edward Rocha de. Teoria das janelas quebradas: e se a pedra vem de dentro?

FERRAJOLI, Luigi. Direito e Razão: teoria do garantismo penal. 3.ed. rev. São Paulo: Revista dos Tribunais, 2010.

online.com.br/canal/direito-e-justica/news/54545/?noticia= . Acessado em: 09/09/2010, através do qual citam as políticas francesas e norte-americanas de se coibir ao máximo qualquer desvio moral do cidadão, para, então, chegar-se a uma sociedade "perfeita", ausente de delitos, por menores que sejam. No entanto, tais políticas não se confirmaram e se dissiparam em uma sociedade que apresenta problemas mais graves que o simples fato de "urinar na rua, beber em público, catar papel, mendicância, prostituição", ou quebrar janelas, como se infere do próprio título.

${ }^{12}$ BECCARIA, Cesare. Dos delitos e das penas. São Paulo: Martin Claret, 2002. p.102. 
LOPES JÚNIOR, Aury. Introdução crítica ao Processo Penal (Fundamentos da instrumentalidade constitucional). 4.ed. Rio de Janeiro: Lúmen Juris, 2006.

MARQUES, José Frederico. Tratado de direito processual penal. v. 2 São Paulo: Saraiva, 1980.

MONTESQUIEU. Do Espírito das Leis, São Paulo: Abril Cultural, 1979.

PACELLI DE OLIVEIRA, Eugênio.Curso de processo penal. 3.ed. Belo Horizonte: Del Rey, 2004.

SARMENTO, George. A presunção da inocência no sistema constitucional brasileiro. In: Direitos fundamentais na Constituição de 1988: estudos comemorativos aos seus vinte anos. Rosmar Antonni Rodrigues Cavalcanti de Alencar (org.). Porto Alegre: Núria Fabris, 2008.

STEIN, Ernildo. Sobre a verdade: lições preliminares ao parágrafo 44 de ser e tempo. Ijuí: Unijuí, 2006.

STRECK, Lenio Luiz. O que é isto - decido conforme minha consciência? Porto Alegre: Livraria do Advogado, 2010.

Novo Código de Processo Penal: o problema dos sincretismos de sistemas (inquisitorial e acusatório). Revista de Informação Legislativa. Brasília: Senado Federal, v.46, n.183, jul./ set. 2009.

TÁVORA, Nestor; ALENCAR, Rosmar Rodrigues. Curso de direito processual penal. 3.ed. Salvador: JusPodivm, 2009.

TOURINHO FILHO, Fernando da Costa. Manual de Processo Penal. 11.ed. São Paulo: Saraiva, 2009. 